\title{
A comparative study of texture and rheology of Argentinian honeys from two regions
}

Ezequiel Maldonado $^{\mathrm{a}}$, Alba S. Navarro ${ }^{\mathrm{a}, \mathrm{b}}$, Diego K. Yamul ${ }^{\mathrm{a}, \mathrm{c}^{*}}$

${ }^{a}$ Centro de Investigación y Desarrollo en Criotecnología de Alimentos (CIDCA), Facultad de Ciencias Exactas, UNLP - CCT La Plata-CONICET, 47 y 116, 1900 La Plata, Argentina.

${ }^{b}$ Facultad de Ingeniería, UNLP, 1 y 47, 1900 La Plata, Argentina.

${ }^{c}$ Departamento de Tecnología y Calidad de los Alimentos, Facultad de Ciencias

Veterinarias, UNICEN, Campus Universitario, 7000, Tandil, Argentina.

\footnotetext{
*Corresponding Author: Diego K. Yamul. Tel/Fax: +54-221-4249287/4254853. E-mail address: karim@biol.unlp.edu.ar.
}

This article has been accepted for publication and undergone full peer review but has not been through the copyediting, typesetting, pagination and proofreading process, which may lead to differences between this version and the Version of Record. Please cite this article as doi: $10.1111 /$ jtxs. 12349 
Running headline: Physical properties of honeys from two regions of Argentina

\begin{abstract}
The rheological and textural properties of 26 eastern Argentinian honeys from two different regions (North and Central) were investigated. The viscosity curves of the samples were obtained using a rotational rheometer over a temperature range of 10 to $50^{\circ} \mathrm{C}$. The viscosity decreased with temperature and all honeys showed a Newtonian behaviour. The temperature dependence of viscosity was described using the Arrhenius, Williams- Landel-Ferry, Vogel-Taumman-Fulcher and Power Law models. The glass transition temperatures of honeys were measured with differential scanning calorimetry and values ranged from -42.63 to $-47.71^{\circ} \mathrm{C}$. The glass transition temperature was also predicted with the Williams- LandelFerry model and no significant differences were observed with the experimental results. Rheological parameters were obtained by small amplitude oscillation experiments. Results indicated that the viscous modulus was higher than the storage modulus within all the frequency ranges assayed and honeys from the North region were more viscous. Results of the back extrusion test showed that honeys from the Central region are harder and both groups of honeys (North and Central) exhibited the same consistency and adhesivity.
\end{abstract}

KEYWORDS: Honey, Rheology, Texture, Glass transition, Viscosity 


\section{PRACTICAL APPLICATION}

The honey chain production starts with the extraction of the product from the combs, pumping it through pipes and finishes at the packaging of the product. During all these stages, honey viscosity is a key parameter to ensure proper processing and quality control, preventing the waste of economic resources. Determining honey viscosity is of great importance for the industry to select the equipment such as pumps, mixers, filters, centrifuges, heat exchangers and optimization of industrial processes. The rheological and textural properties of honey are very important in terms of applications related to quality control and authenticity of honeys. Honey authenticity increases the trust of consumers to certified food products. Argentina is one of the leading honey producers and exporters in the world, but information on the rheological, thermal and textural characteristics of Argentinian honey is very poor in the scientific literature. 


\section{INTRODUCTION}

Chemically, honey is comprised of sugars ( $80-85 \%)$, water (15-20\%), and other minor constituents such as minerals, proteins, phenolic compounds, organic acids, and free amino acids (Akbulut et al. 2012). The composition is influenced mainly by the dominant flora around the apiaries (Silvano et al. 2014) and furthermore by the geographic region (Patrignani et al. 2015), weather, and type of soil (Oroian et al. 2013a). Temperature and moisture content have a strong influence on honey viscosity; however, factors like its chemical composition, are also important. The honey chain production starts with the extraction of the product from the combs, pumping it through pipes and finishes at the packaging of the product. During all these stages, honey viscosity is a key parameter to ensure a proper process. When honey is subjected to steady shear viscosimetry experiments, a Newtonian fluid behaviour is often found. However, there are few reports describing thixotropic and dilatant characteristics (Juszczak and Fortuna 2006; Osés et al. 2017). Dynamic measurements are also useful tools to analyse the rheological characteristics of honey without much alteration in the internal network structure. Kayacier and Karaman (2008), Da Silva et al. (2016) and Ahmed et al. (2007) used small amplitude dynamic oscillatory measurements on honey samples and observed a liquid-like behaviour with loss modulus greater than storage modulus within all the frequency range assayed.

As temperature increases, viscosity falls due to less molecular friction and reduced hydrodynamic forces (Juszczak and Fortuna 2006). Commonly, the Arrhenius equation has been used to describe temperature dependency of honey samples (Kayacier and Karaman 2008 in Turkish honeys; Da Silva et al. 2016 in Brazilian honeys; Juszczak and Fortuna 2006 in Polish honeys; Sopade et al. 2002 in Australian honeys; Belay et al. 2017 in Ethiopian honeys). However, this model renders a relatively higher value of activation energy (Al- 
Malah et al. 2001). On the other hand, models like the William-Landel-Ferry (WLF), VogelTaumman-Fulcher (VTF) and Power Law, has been used successfully to describe the temperature dependence of honey viscosity (Sopade et al. 2002; Lazaridou et al. 2004; Juszczak and Fortuna 2006, Recondo et al. 2006, Oroian et al. 2013a,b). Glass transition is a phenomenon that occurs when a material changes from the rubbery state (viscous fluid) to the glassy state (mechanical solid) during cooling and it is a second order phase transition (Al-Malah et al. 2001; Sopade et al. 2002). The $T g$ can be experimentally determined by differential scanning calorimetry, but the high viscosity $\left(10^{7}-10^{14} \mathrm{~Pa}\right.$.s, as reported by Sopade et al. 2002) of the glassy state makes the experimental determination of the $\eta_{T g}$ impossible. However, it is possible to use some extrapolation procedures to estimate the value of the $\eta_{T g}$ (Bhandari et al. 1999; Peleg 1992).

Moisture in honeys is a parameter related to the climatic conditions, geographical origin, handling, storage and degree of maturity. The Codex Alimentarius (2017) establishes a maximum acceptable moisture content of $20 \mathrm{~g} / 100 \mathrm{~g}$. However, water in honey could be as high as $29 \mathrm{~g} / 100 \mathrm{~g}$ or as low as $13 \mathrm{~g} / 100 \mathrm{~g}$ (Junzheng and Changying, 1998; White, 1975) A $1 \mathrm{~g} / 100 \mathrm{~g}$ change in water content has the same effect on honey viscosity as a $3.5^{\circ} \mathrm{C}$ change in temperature (Juszczak and Fortuna 2006). Thus, the higher the water content the lower the honey viscosity.

The objective of this study is to investigate the application of the viscosity-temperature describing models to honeys from two different phytogeographic regions of Argentina: The North and Central regions. The rheological behaviour at different temperatures and textural characteristics of honeys are also analysed. 


\section{MATERIALS AND METHODS}

\section{Honey samples}

The present study was performed on 26 samples (13 from the East Central, Buenos Aires province and 13 from the North-East, Chaco province) of multiflora honeys. The selection of the beehives to obtain the samples was performed according to a simple random sampling design. Honey samples, harvested in January 2015, were obtained by cold extraction and immediately stored at $4^{\circ} \mathrm{C}$ in plastic containers until analysis. Before all determinations, samples were heated in closed containers during 1 hour at $45^{\circ} \mathrm{C}$ to melt any crystals that were present and to remove the air bubbles.

\section{Moisture content, Brix degrees and sugars profile analysis.}

Refractive index of honeys was measured at $20^{\circ} \mathrm{C}$ using an Abbe refractometer and the corresponding moisture content was calculated from the Chatway Table (AOAC 1990). The Brix degrees ( ${ }^{\circ}$ Brix) were measured with a portable refractometer (Hanna Instruments HI 96801, USA). Sugar analysis was performed as described by Silvano et al. (2014).

\section{Differential scanning calorimetry}

The glass transition temperature ( $T g$ ) of honeys was determined using a differential scanning calorimeter (DSC) (Thermal Analysis Instruments, New Castle, Delaware, USA) calibrated with indium. Twelve samples (six from the North and six from the Central region) of about $20 \mathrm{mg}$ each were placed in aluminium DSC hermetic pans. . A sealed empty aluminium pan was used as a reference (Da Silva et al. 2018; Leo and Nollet, 2015). The experiment was performed as described by Lazaridou et al. 2004: the samples were heated from 20 to $50^{\circ} \mathrm{C}$ at 
a heating rate of $10^{\circ} \mathrm{C} / \mathrm{min}$ and kept at $50^{\circ} \mathrm{C}$ for $5 \mathrm{~min}$ to ensure the melting of any crystals. The samples were then quench-cooled with liquid $\mathrm{N}_{2}$ to $-80^{\circ} \mathrm{C}$ and reheated to $50^{\circ} \mathrm{C}$ at the same heating rate. The $T g$ was determined, using the $T g$ command of the TA Instruments Universal Analysis 2000 software version 4.2E.

\section{Rheological measurements}

Rheological properties of honey were investigated with a RS 600 controlled stress rheometer (Haake, Karlsruhe, Germany) using a $1.0 \mathrm{~mm}$ gap parallel plate geometry. Samples were placed on the lower plate and temperature was regulated by a Haake (Karlsruhe, Germany) circulating water bath. After loading the sample, a waiting period of 5 min was necessary to allow the sample to recover and to reach the specified temperature. Small amplitude oscillation stress experiments were performed to obtain the storage $\left(G^{\prime}\right)$ and viscous $\left(G^{\prime \prime}\right)$ moduli and complex viscosity $\left(\eta^{*}\right)$ at a strain level of $0.5 \%$ (within the linear viscoelastic range) and a range of angular frequencies $(\omega)$ of $0.4-600 \mathrm{rad} \mathrm{s}^{-1}$ at $20^{\circ} \mathrm{C}$. The flow behaviour was studied by measuring steady shear viscosity $(\eta)$ and shear stress $(\tau)$ over a range of shear rates $(\gamma)$ of $0.1-400 \mathrm{~s}^{-1}$ at $10,20,30,40$ and $50^{\circ} \mathrm{C}$. For each sample, two independent replicates were assayed. Temperature effects on $\eta$ were analysed using the following models:

Arrhenius relationship:

$\eta=\eta_{0} \times e^{(E a / R T)}$

where $\eta$ is the viscosity at temperature $T, \eta_{0}$ is a pre-exponential factor, $E_{a}$ is the activation energy for flow, $R$ is the perfect gas constant and $T$ is the absolute temperature. 
Willian-Landel Ferry model (Willian et al. 1955):

$\log \left(\eta / \eta_{T g}\right)=\left[-C_{1}(T-T g)\right] /\left[C_{2}+(T-T g)\right]$

where $T g$ is the glass transition temperature, $\eta$ is the viscosity at temperature $T, \eta_{T g}$ is the viscosity of sample at $T g$ or glass viscosity and $C_{1}$ and $C_{2}$ are the WLF model constants.

The Vogel-Taumman-Fulcher model (Sopade et al. 2002).

$\eta=A \times \exp (B /(T-T g))$

where $A$ is the pre-exponential factor $T g$ is the glass transition temperature. $A$ and $B$ were calculated as the slope of the linearized form of Eq. 3 .

The Power Law model:

$\eta=K \times(T-T g)^{-m}$

where $K$ and $m$ are constants estimated from linearization of Eq. 4.

\section{Textural measurements: back extrusion}

Back extrusion tests were carried out as suggested by Conforti et al. (2006) using a TA.XT2 Texture analyser (Stable Micro Systems Ltd., Surrey, UK) with a cylindrical container of $45 \mathrm{~mm}$ internal diameter filled with honey, in which the compression probe ( $35 \mathrm{~mm}$ diameter) moved at a speed of $0.5 \mathrm{~mm} / \mathrm{s}$ until $30 \%$ deformation. Sample hardness was defined as the maximum height of the peak of the force versus time/deformation curve. The area of first peak is the consistency of the sample. The negative force area obtained after the compression cycle is defined as the adhesivity (Figure 1). For each sample, three independent replicates were assayed. 


\section{Data analysis}

Rheological data were fitted using the software Origin Pro 8 v8.0724 (Origin Lab Corporation, MA, USA).

Analysis of variance was performed and the least significant differences were calculated to compare the means of both groups of honeys (North and Central) at a $95 \%$ level using the Fisher test. A $p$-value of less than 0.05 was considered significant.

Cluster analysis was performed on the standardised data to classify samples based on the similarities of their rheological and textural parameters and moisture content. Clusters were calculated using the Euclidian distance and the Ward technique. The Infostat software 2014e version (Córdoba National University, Córdoba, Argentina) was used.

\section{RESULTS AND DISCUSSION}

\section{Rheological characteristics}

Fig. 1a,b shows the steady shear flow rheograms of selected honey samples at $20^{\circ} \mathrm{C}$.

Generally, the $\eta$ did not change and $\tau$ linearly increased with $\gamma$ indicating a Newtonian behaviour similar to Kayacier and Karaman (2008), Da Silva et al. (2016), Sopade et al. (2002) and Belay et al. (2017). Fig. 1c illustrates the mechanical spectrum of selected honey samples at $20^{\circ} \mathrm{C}$. It was observed that $G$ ', was higher than $G$ ' within all the frequency ranges assayed, except at very high frequencies in which both moduli have similar values. High values of $G$ '” confirm the viscous nature of honey and the low values of $G$ ' suggest that there was no network formation in honey samples due to weak particle -particle interactions 
(Ahmed et al. 2007). This response is typical of liquid-like materials, characterized as viscous fluids (Yamul and Lupano, 2009). As a result of the viscous nature of honey, changes in $G$ ' with frequency provide more information than $G$ ' [Figure 1 here]. Honeys from the North region are more viscous $(p<0.05)$ than those from the Central as reflected by the results for $\eta, G^{\prime \prime}$ and $\eta^{*}$ (Fig. 2 b,c,d). These differences could be attributed to natural variations in honey composition. The north of Argentina has a tropical climate with hot and wet summers, determining the flora of the area and, thus, the nectar composition used by bees to produce honey. In addition, higher temperatures and environmental moisture might also influence the maturation of honey in the beehive, affecting its physico-chemical properties and leading to differences in honeys from these different regions.

Figure 2e shows that the values of $\eta$ and $\eta^{*}$ of honeys from both regions are similar at equivalent numerical values of angular frequency and shear rate. This result suggests that these honeys follow the Cox-Merz rule (Cox and Merx 1958), which is expected for Newtonian liquids without particle-particle interactions. Lazaridou et al. (2004) reported a similar behaviour in Greek honeys. [Figure 2 here]

Moisture, which is a parameter related to several climatic conditions, handling of honey by the producer and degree of maturity (Silvano et al. 2014), decreased the viscosity of honey (Fig. 3). Honeys from the North (Fig. 3a) show a weak linear fit between viscosity and honey moisture content with an $r^{2}$ value of 0.6436 , which is comparable to the $r^{2}$ value of 0.6369 obtained by Belay et al. (2017) in Ethiopian honeys. On the other hand, honeys from the Central region (Fig. 3b) show a greater dispersion of the data and it is not possible to fit them to a straight line with a satisfactory $r^{2}$. It is interesting to note that Lazaridou et al. (2004) also found a decrease of the viscosity as water content increased but fitted data to a decreasing exponential function. [Figure 3 here]. 


\section{Moisture content, sugar analysis, Brix degree and glass transition temperature of honeys.}

The effect of moisture content on the $T g$ is shown in Table 1. Results show mean values of $17.95 \mathrm{gH}_{2} \mathrm{O} / 100 \mathrm{~g}$ and $18.55 \mathrm{gH}_{2} \mathrm{O} / 100 \mathrm{~g}$ for honeys from the North and Centre of the country, respectively. Samples shown in Table 1 agree with the requirements of the Codex Alimentarius (2017) which sets the maximum value of that parameter at $20 \mathrm{gH}_{2} \mathrm{O} / 100 \mathrm{~g}$. Water is a universal plasticizer, which decreases the $T g$ due to its ability to weaken noncovalent interactions (Matveev et al. 2000). It is generally accepted that $T g$ is a function of both moisture and solid content. Sopade et al. (2002) and Lazaridou et al. (2004) found a strong dependence of $\mathrm{Tg}$ with water content in honeys from Australia and Greece, respectively. [Table 1 here]

Table 2 shows the composition of the most abundant sugars identified in the honey samples. As expected, fructose and glucose represent the main sugars, covering more than $65 \%$ of the total carbohydrates. Therefore, all honeys were in agreement with the requirements of the Codex Alimentarius (2017). Honeys from the Central region has significantly $(\mathrm{p} \leq 0.05)$ higher values of fructose and glucose content than honeys from the North, but no significant differences $(\mathrm{p} \geq 0.05)$ were obtained in the content of the disaccharides sucrose and maltose. Fructose/Glucose ratio is an indicator of honey granulation because glucose is less water soluble than fructose (Bentabol Manzanares et al. 2011). When this ratio is higher than 1.5 honey remains liquid for longer periods (Ouchemoukh. et al. 2010). Honeys from the northern region showed higher values of fructose/glucose ratio (1.54) suggesting that these honey samples remains liquid for longer times. [Table 2 here]. 
The ${ }^{\circ}$ Brix is an estimation of the sugar (solid) content of an aqueous solution, thus, the higher the ${ }^{\circ}$ Brix the lower the water content and the higher the Tg. Ahmed et al. (2007) found higher $T g$ values in honeys with higher solid content. Results in Table 1 show no significant differences $(p>0.05)$ in the mean values of $T g$ of honeys from both regions. This is an expected result because honeys also show no significant differences $(p>0.05)$ in the moisture content and ${ }^{\circ}$ Brix. Venir et al. (2010), Recondo et al. (2006) and Oroian et al. (2013b) reported similar values of $T g$ at similar soluble solids content (80-81g/100g). In contrast, Ren et al. (2010) reported a lower value of $\operatorname{Tg}\left(-49.5^{\circ} \mathrm{C}\right)$ in Chinese honey containing $75 \mathrm{~g} / 100 \mathrm{~g}$ of soluble solids.

\section{Temperature dependence of viscosity: Arrhenius, VTF, Power law and WLF models.}

As a Newtonian liquid, honey viscosity substantially reduced when temperature was increased (Fig. 1d). Viscosity values were similar to those obtained by Da Silva et al. (2004) and Sopade et al. (2002) at the same temperatures. The Arrhenius relationship (Eq. (1)) is a useful tool to estimate the temperature dependence of viscosity. Many authors used this model for diverse types of honeys (Kayacier and Karaman 2008; Nayik et al. 2016; Oroian et al. 2013b; Recondo et al. 2006). The Ea, which is derived from the Arrhenius formalism (Lazaridou et al. 2004), reflects the sensitivity of viscosity to temperature changes. Table 3 (supplementary material) shows no significant differences $(p>0.05)$ in the mean values of $E a$ suggesting that both types of honeys need the same energy to flow, in spite of the fact that honeys from the North are more viscous as suggested above. The mean values of $E a$ were $79.61 \mathrm{~kJ} \mathrm{~mol}^{-1}$ and $82.09 \mathrm{~kJ} \mathrm{~mol}^{-1}$ for North and Centre, respectively. These were similar to those reported in the literature (Oroian et al. 2013b; Recondo et al. 2006; Lazaridou et al. 2004; Sopade et al. 2002; Kayacier and Karaman 2008). The pre-exponential factor in the 
Arrhenius equation, according to Al-Malah et al. (2001), represents viscosity at a

temperature close to infinity. The values obtained were lower than those reported by Oroian et al. (2013b).

The viscosity vs. temperature relationship was also described using the VTF and Power law models. The values of the constants of both models $(A, B, K$ and $m$, Table 3 supplementary material) were different from those reported by Recondo et al. (2006). The difference could be related to the fact that, these authors, used unifloral honey from Bulnesia sarmientoi (algarrobo), while we used multiflora honey.

Concentrated sugar solutions obey the WLF equation (Soesanto and William 1981), thus, honey due to its high sugar content could be adequately described using this model. Prevoius results (Lazaridou et al. 2004; Recondo et al. 2006; Sopade et al. 2002; Juszczak and Fortuna 2006) indicate that the WLF model has been useful to describe viscosity-temperature data of honeys from different origins. Compared to the Arrhenius relationship, the WLF equation is a more appropriate model to describe viscosity-temperature dependence between $T_{g}$ and about $T_{g}+100^{\circ} \mathrm{C}$. Moreover, the WLF model specifies a much stronger temperature dependence of viscosity compared to that predicted by the Arrhenius formalism (Lazaridou et al. 2004). Viscosity data ( $\eta$ vs $T$ ) of 12 honey samples ( 6 from the North and 6 from the Centre region) were fitted to the WLF equation (Table 1). Using the universal values for the constants $\left(C_{1}=17.44\right.$ and $C_{2}=51.6 \mathrm{~K}$; William et al. 1955), the results of the predicted $\mathrm{Tg}$ show good fits $\left(r^{2}>0.90\right)$ in almost all samples analysed. Al-Malah et al. (2001) and Lazaridou et al. (2004) obtained similar fit when describing the temperature dependence of honey viscosity using the WLF equation. The predicted $T g$ values are not significantly different $(p>0.05)$ with the values obtained experimentally by DSC (Table 1, mean values of $T g$ ). On the other hand, Lazaridou et al. (2004) explain that the differences between the 
experimental and predicted values could lie on the fact that $\mathrm{Tg}$ reflects a range of temperatures and, thus depends on the technique and experimental conditions used for its determination. Recondo et al. (2006) obtained a $\mathrm{Tg}$ value much lower $\left(-59.7^{\circ} \mathrm{C}\right.$, unifloral honey from Bulnesia sarmientoi) than our results (Table 1) probably due to the differences in the honeys analysed. However, when these authors used the reduced constants (i.e., constants calculated by the reduced model method, Recondo et al. 2006), they obtained a value of $45.2^{\circ} \mathrm{C}$ that is similar to our values of $T g$.

The predicted $\eta_{T g}$ values ranged between $10^{10.34}$ and $10^{11.96} \mathrm{~Pa}$.s for both regions and are similar to the values reported by Sopade et al. (2002) and lower than the values reported by Recondo et al. 2006. In contrast with the $T g$, which could be measured by different techniques, the glass viscosity could be only estimated from the model because such high values are not accessible for any existing rheometer (Lazaridou et al. 2004).

The universal values for $C_{1}$ and $C_{2}$ are average values obtained from data on many glassforming liquids and sometimes their use might not be successful with other samples. Sopade et al. (2002) claimed that $C_{1}$ and $C_{2}$ should not be fixed constants for comparison of the temperature sensitivity among different samples of honey. When the constants were allowed to vary (without using the universal values), and $T g$ from the DSC was used as the reference temperature (Table 1), very good fits $\left(r^{2}>0.96\right)$ were obtained for $C_{1}$ and $C_{2}$, except for 3 samples from the north region with $r^{2}$ ranging from 0.77 to 0.88 . The mean values of $C_{1}$ and $C_{2}$ (shown in Table 1) for both regions are comparable to those obtained by Lazaridou et al. (2004). On the other hand, values of the $\eta_{T g}$ were much higher $\left(10^{18.29}\right.$ Pa.s North and $10^{20.22}$ Pa.s Centre) than those obtained using the universal values for $C_{1}$ and $C_{2}\left(10^{11.12}\right.$ Pa.s North and $10^{11.07}$ Pa.s Central). These results do not likely represent the true values. Peleg (1992) reported that the magnitude of $C_{1}$ and $C_{2}$ might vary considerably from the universal values 
depending on the material studied, the measured property and the reference temperature. In addition, it is interesting to note that, independent of the geographic origin of honeys, values of the predicted parameters using the WLF equation showed no significant differences ( $p>$ $0.05)$.

It is interesting to note that regardless of the model used some honeys from the North usually presented weaker fits to the models as reflected by those with $r^{2}$ values lower than 0.85 (Table 3 supplementary material).

\section{Back extrusion test of honeys}

Rheological properties of fluids or semisolid foods are typically assayed in a rheometer; however, the texture analyser could be used in these types of foods to carry out the back extrusion test. In this test, the sample is placed in a cylindrical container and subjected to compression to obtain the force vs time curve, which could be used to calculate the maximum force and adhesivity of the sample. Conforti et al. (2006) used back extrusion and Oroian et al. $(2016,2017)$ used texture profile analysis to study the fluid properties of honey. Figure 4a shows that honeys from the Central region are harder than those from the North, which is in agreement with the rheology results. The higher hardness would be, as suggested by Conforti et al. (2006), the result of a higher sugar concentration in samples from the Central region. This fact could be confirmed with the results of Table 2 . Table 4 (supplementary material) shows a higher correlation between hardness and sugars (glucose, sucrose and maltose) in honeys from the Central region confirming the results above. The influence of fructose on hardness is insignificant in honeys from both regions. On the contrary, Oroian et al. (2016) found significant influence of fructose on textural parameters. It is interesting to note that maltose has the highest correlation with textural parameters of 
honeys from both regions. Sugars depict a weak correlation with viscosity in honeys from both regions. The correlation of the ratio $\mathrm{F} / \mathrm{G}$ with textural parameters is also higher in honeys from the Central region. The ratio $\mathrm{F} / \mathrm{G}$ also has negative and positive associations with the viscosity of honeys from the Centre and North respectively. Consistency, which is related to 'thickness' or 'viscosity' of a liquid or semi-solid fluid, is commonly the textural property of dairy products, sauces and syrups. It is interesting to note that consistency shows a weak correlation with viscosity but a high correlation with hardness (Table 4 supplementary material). The results in Figure $4 \mathrm{~b}$ show no significant differences $(p>0.05)$ in the consistency of honeys from both regions. Adhesivity is related to the negative extrusion force required for withdrawal of the probe away from the sample. Figure $4 \mathrm{c}$ shows that honey from both regions have no significant differences $(p>0.05)$ in their adhesive properties [Figure 4 here]. Figure 5a,b shows an inverse linear relationship obtained between the adhesivity and hardness of honey samples from both regions, with $r^{2}$ values of -0.928 and -0.910 for the North and Central regions, respectively. These results are similar to the Pearson correlation between adhesivity and hardness (Table 4 supplementary material). On the other hand, Oroian et al. (2016) also obtained a high Pearson correlation between these textural parameters but positively influenced one by the other. Honeys might adhere to the surface of the probe due to interatomic forces and non-covalent interactions. It is possible that in harder honeys the interactions with the metal of the probe are weaker due to stronger interactions in the honey structure. Conforti et al. (2006) found that honeys with higher values of hardness have lower moisture contents, which could be attributed to the higher sugar concentration in non-crystallised honey. However, our results (Fig. 5c,d) show a scattered point distribution with no clear trend between hardness and moisture 
content.[Figure 5 here]. These results could be confirmed with the weak Pearson correlation obtained between hardness and moisture (Table 4 supplementary material).

\section{Cluster analysis}

The classification techniques based on groupings involves the distribution of study units in classes or categories in such a way that each class (conglomerate) brings together units whose similarity is recognizable under certain given criterion (Balzarini et al 2008). Figure 6 shows the cluster analysis and, at 75\% (15) of the total range distance, two clusters are observed. One of them includes the samples from the North region and, the other one, the samples from the Central region Centre region. From 23 samples, some of them were misclassified using the cluster analysis. Samples C6, C10, C11 and C12 were included in the group from the North region. On the other hand, N3 and N8 were grouped as Central region samples. [Figure 6 here]

\section{CONCLUSIONS}

Honeys from the North and Centre of eastern Argentina behaved as Newtonian fluids, although some differences in their rheological behaviours were found. Honeys from the North were more viscous than those from the Central region as reflected by their $\eta, E_{a}, G$ ", and $\eta^{*}$ values. Moisture content decreased the viscosity of honeys from the North region, but its effect on honeys from the Central region was not well defined. Values of the glass transition temperature obtained from the DSC and those predicted by the WLF model were comparable for both regions. Arrhenius, WLF, VTF and Power Law models proved to be adequate to describe the viscous behaviour of honey as a function of temperature, except with some honeys from the North, which showed a weak fit to the models. The back- 
extrusion test could be useful to analyse the textural characteristics of viscous foods like honey. On the other hand, the effect of moisture on hardness was not very clear. Cluster analysis showed a weak classification of honey samples based on rheological and textural parameters.

\section{ETHICAL STATEMENT}

The authors declare that they do not have any conflict of interest.

This study does not involve any human or animal testing

Written informed consent was obtained from all study participants.

\section{ACKNOWLEDGMENTS}

The authors would like to thank the financial support from CONICET

Mr. Eng. Christopher Young for checking the English language. 


\section{REFERENCES}

Ahmed, S., Prabhu, S.T., Raghavan, G.S.V., \& Ngadi, M. (2007). Physico-chemical, rheological, calorimetric and dielectric behavior of selected Indian honey. Journal of Food Engineering, 79, 1207-1213. doi: 10.1016/j.jfoodeng.2006.04.048

Akbulut, M., Saricoban, C., \& Ozcan, M. M. (2012). Determination of Rheological Behavior, Emulsion Stability, Color, and Sensory of Sesame Pastes (Tahin) Blended with Pine Honey. Food and Bioprocess Technology, 5, 1832-1839. doi 10.1007/s11947-0110668-6

Al-Malah, K.I.M., Abu-Jdayil, B., Zaitoun, S., \& Ghzawi, A.M. (2001). Application of WLF and Arrhenius kinetics to rheology of selected dark-colored honey. Journal of Food Process Engineering, 24, 341-357.

AOAC (1990). Official methods of analysis. Arlington, VA: Association of Official Analytical Chemists.

Bentabol Manzanares, A., Hernández García, Z., Rodríguez Galdón, B., Rodríguez Rodríguez, E., \& Díaz Romero, C. (2011). Differentiation of blossom and honeydew honeys using multivariate analysis on the physicochemical parameters and sugar composition. Food Chemistry, 126, 664-672. https://doi.org/10.1016/j.foodchem.2010.11.003 
Bhandari, B., D’Arcy, B., \& Kelly, C. (1999). Rheology and crystallisation kinetics of honey: Present status. International Journal of Food Properties, 2, 217-226.

Belay, A., Haki, G.D., Birringer, M. Borck, H. Addi, A., Baye, K., et al. (2017). Rheology and botanical origin of Ethiopian monofloral honey. LWT - Food Science and Technology, 75, 393-401. http://dx.doi.org/10.1016/j.lwt.2016.09.021

Conforti, P.A., Lupano, C.E., Malacalza, N.H., Arias, V., \& Castells, C.B. (2006). Crystallization of Honey at $-20^{\circ}$ C. International Journal of Food Properties, 9, 99-107. doi: $10.1080 / 10942910500473962$

Codex Alimentarius (2017). Standard for honey. http://www.codexalimentarius.org/. Accessed: December 2017.

Cox, W.P., \& Merz, E.H. (1958). Correlation of dynamic and steady shear flow viscosities. Journal of Polymer Science, 28, 619-622.

Da Silva, V. M., De Carvalho, L. A., De Oliveira, N. L., De Almeida Torres Filho, R., \&, De Resende J. V. (2016). Rheological and termal properties of selected brazilian honeys from varoius floral origins. Journal of Texture Studies, 47, 208-219. doi:10.1111/jtxs.12174

Da Silva, V. M. Almeida Torres Filho, R., \& Vilele de Rosende, J. (2018). Rheological properties of selected Brazilian honeys as a function of temperature and soluble solid 
concentration. International Journal of Food Properties, 20, 2481-2494.

https://doi.org/10.1080/10942912.2017.1370599

Juszczak, L., \& Fortuna, T. (2006). Rheology of selected Polish honeys. Journal of Food

Engineering, 75, 43-49. doi:10.1016/j.jfoodeng.2005.03.049

Junzheng, P., \& Changying, J. (1998). General rheological model for natural honeys in China. Journal of Food Engineering, 36, 165-168.

Kayacier, A., \& Karaman, S. (2008). Rheological and some physicochemical characteristics of selected Turkish honeys. Journal of Texture Studies, 39, 17-27. doi:10.1111/jtxs.12174

Lazaridou A, Biliaderis C.G, Bacandritsos, N., Sabatini, A.G. (2004). Composition, thermal and rheological behaviour of selected Greek honeys. Journal of Food Engineering, 64, 9-21. doi:10.1016/j.jfoodeng.2003.09.007

Leo, M.L \& Nollet, F.D. (2015). Handbook of Food Analysis ( $3^{\text {rd }}$ ed). Abingdon, OX: CRC Press Taylor and Francis group.

Matveev, Y.I., Grinberg, V.Y., \& Tolstoguzov, V.B. (2000). The plasticizing effect of water on proteins, polysaccharides and their mixtures. Glassy state of biopolymers, food and seeds. Food Hydrocolloids, 14, 425-437. 
Nayik, G.A., Dar, B.N., \& Nanda, V. (2016). Rheological behavior of high altitude Indian honey varieties as affected by temperature. Journal of the Saudi Society of Agricultural Sciences, in press, http://dx.doi.org/10.1016/j.jssas.2016.07.003

Osés, S. M., Ruiz, M. O., Pascual-Maté, A., Bocos, A., Fernández-Muiño, M. A., \& Sancho, M. T. (2017). Ling Heather Honey Authentication by Thixotropic Parameters. Food and Bioprocess Technology, 10, 973-979. doi: 10.1007/s11947-017-1875-6

Oroian, M., Amariei, S., Escriche, I. \& Gutt, G. (2013a). A Viscoelastic Model for Honeys Using the Time-Temperature Superposition Principle (TTSP). Food Bioprocess Technology, 6, 2251-2260. doi: 10.1007/s11947-012-0893-7

Oroian, M., Amariei, S., Escriche, I., \& Gutt, G. (2013b). Rheological Aspects of Spanish Honeys. Food and Bioprocess Technology, 6, 228-241. doi: 10.1007/s11947-011-0730-4

Oroian, M., Paduret, S., Amariei, S., \& Gutt, G. (2016). Chemical composition and temperature influence on honey texture properties. Journal of food science and technology, 53, 431-440. doi: 10.1007/s13197-015-1958-1

Oroian, M., Ropciuc, S., Paduret, S., \& Sanduleac, E. T. (2017). Authentication of Romanian honeys based on physicochemical properties, texture and chemometric. Journal of food science and technology, 54, 4240-4250. doi: 10.1007/s13197-017-2893-0

Ouchemoukh, S., Schweitzer, P., BachirBeya, M., Djoudad-Kadji, H., \& Louaileche, H. 
(2010). HPLC sugar profiles of Algerian honeys. Food Chemistry, 121, 561-568.

https://doi.org/10.1016/j.foodchem.2009.12.047

Patrignani, M., Bernardelli, C., Conforti, P.A., Malacalza, N.H., Yamul, D.K., Donati, E., Lupano, C. E. (2015). Geographical discrimination of honeys through antioxidant capacity, mineral content and color. International Journal of Food Science and Technology, 50, 25982605. doi:10.1111/ijfs. 12928

Peleg, M. (1992). On the use of the WLF model in polymers and foods. Critical Reviews in Food Science and Nutrition, 32, 59-66.

Recondo, M. P., Elizalde, B. E., \& Buera, M. P. (2006). Modeling temperature dependence of honey viscosity and of related supersaturated model carbohydrate systems. Journal of Food Engineering, 77, 126-134. doi:10.1016/j.jfoodeng.2005.06.054

Ren, Z., Bian, X., Lin, L., Bai, Y., \& Wang, W. (2010). Viscosity and melt fragility in honey-water mixtures. Journal of Food Engineering, 100, 705-710. doi:10.1016/j.jfoodeng.2010.06.004

Silvano, M.F; Varela, M.S; Palacio, M.A; Ruffinengo, S., \& Yamul, D.K. (2014).

Physicochemical parameters and sensory properties of honeys from Buenos Aires region. Food Chemistry, 152, 500-507. http://dx.doi.org/10.1016/j.foodchem.2013.12.011 
Sopade, P.A., Halley, P., Bhandari, B., D’Arcy, B., Doebler, C., \& Caffin, N. (2002).

Application of the Williams-Landel-Ferry model to the viscosity-temperature relationship of Australian honeys. Journal of Food Engineering, 56, 67-75. doi:10.1016/S02608774(02)00149-8

Soesanto, T., \& Williams, M. C. (1981). Volumetric interpretation of viscosity for concentrated and dilute sugar solutions. Journal of Physical Chemistry, 85, 3338-3341.

Venir, E., Spaziani, M., \& Maltini, E. (2010). Crystallization in “Tarassaco” Italian honey studied by DSC. Food Chemistry, 122, 410-415. doi:10.1016/j.foodchem.2009.04.012

White, J. W. (1975). Physical characteristics of honey. In E. Crane (Ed.), Honey: A comprehensive survey (pp. 207-239). London: Morrison and Gibbs Ltd.

Williams, M. L., Landel, R. F., \& Ferry, J. D. (1955). The temperature dependence of relaxation mechanisms in amorphous polymers and other glass-forming liquids. Journal of the American Chemical Society, 77, 3701-3707.

Yamul, D.K., \& Lupano, C.E. (2009). Viscoelastic properties of whey protein concentrate gels with honey and wheat flour at different pH. Journal of Texture Studies, 40, 319-333. doi: $10.1111 /$ j.1745-4603.2009.00184.x 

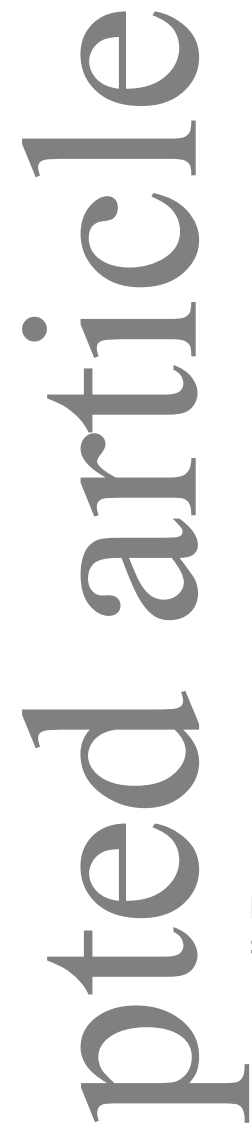

Figure 2. i) Storage modulus ( $\left.G^{\prime}\right)$; ii) Loss modulus ( $\left.G^{\prime \prime}\right)$; iii) Complex viscosity $\left(\eta^{*}\right)$ (measured at $\omega=10$ rad $s-1)$; iv), Steady shear viscosity ( $\eta)$; v) and vi) Comparative values of $\eta$ and $\eta^{*}$ at $20^{\circ} \mathrm{C}$ of honeys from both regions; $\eta$ : bars with horizontal lines and $\eta *$ : bars with vertical lines. Values with the same letter in the same graph are not significantly different $(p>0.05)$. 

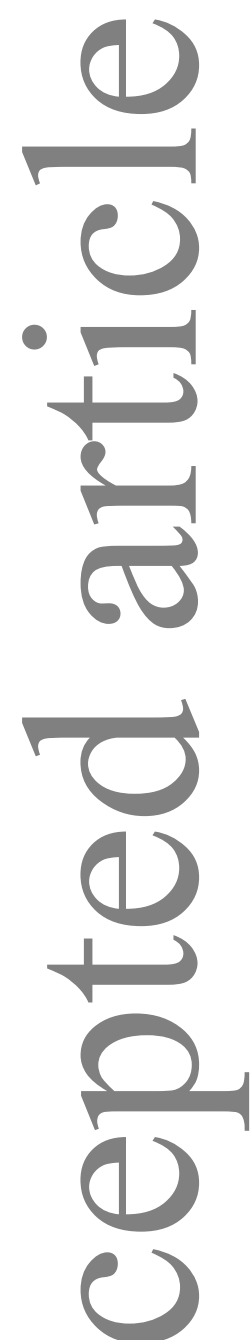

8
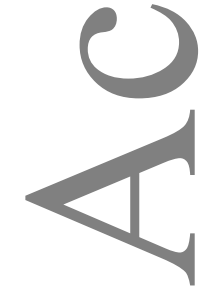
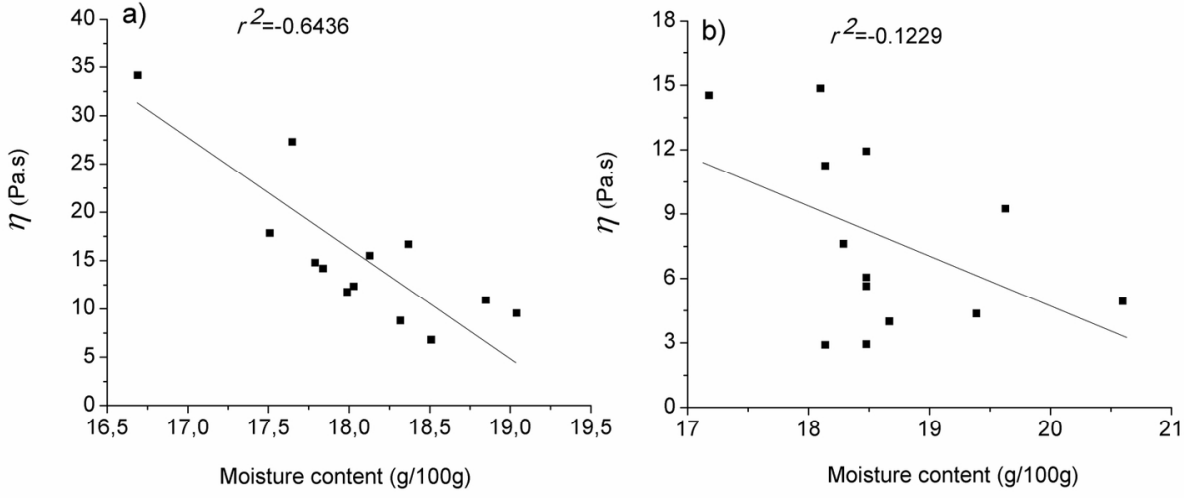

Figure 3. Linear fit showing the associations between steady shear viscosity $(\eta)$ and moisture content of honeys. a) North region, b) Central region. 

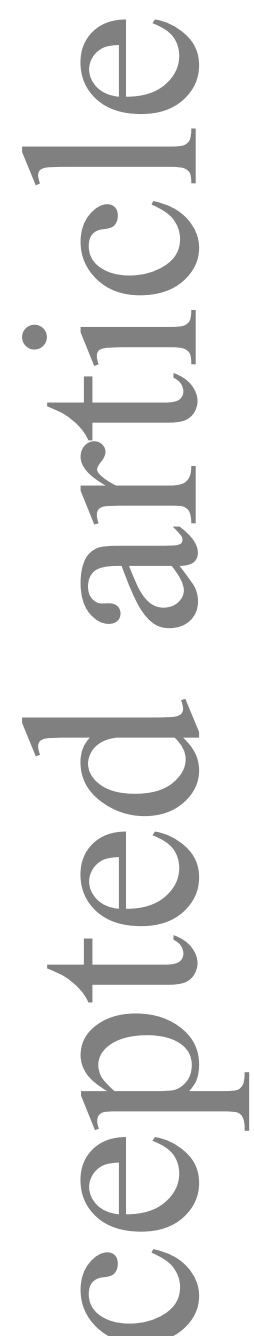

ల

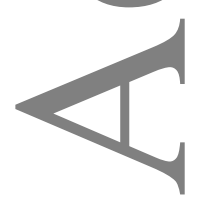

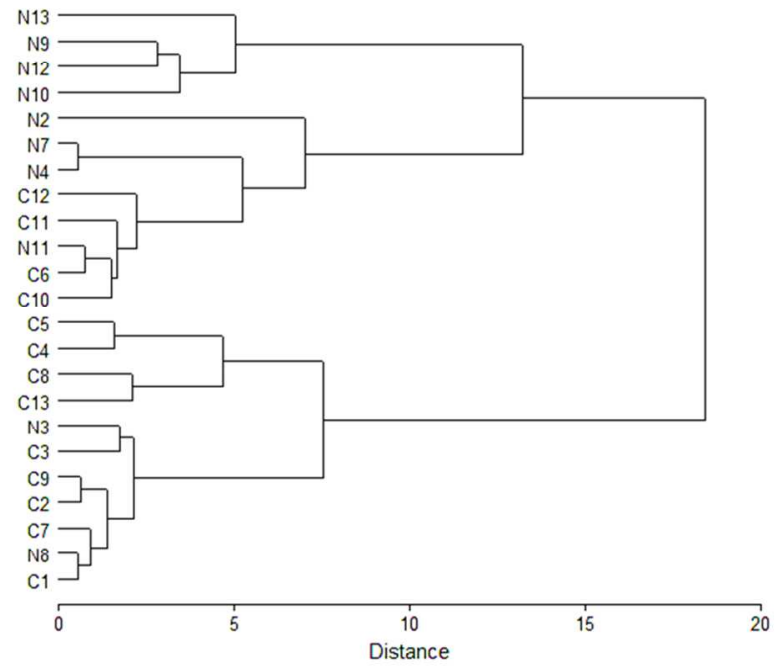

Figure 6. Dendrogram of cluster analysis. N: North region, C: Central region. 
Table 1. Moisture content, ${ }^{\circ}$ Brix, glass transition temperatures (Tg) and estimated parameters of the WLF model of honeys from North $(\mathrm{N})$ and Central region $(\mathrm{C})$ of Argentina. Values with the same letter in the same column are not significantly different $(\mathrm{p}>0.05)$.

r

\begin{tabular}{|c|c|c|c|c|c|c|c|c|c|c|}
\hline mple & $\begin{array}{l}\text { Moisture content } \\
\left(\mathrm{gH}_{2} \mathrm{O} / 100 \mathrm{~g}\right)\end{array}$ & $\begin{array}{c}{ }^{\circ} \text { Brix } \\
(\mathrm{g} / 100 \mathrm{~g})\end{array}$ & $\begin{array}{c}\mathrm{Tg}, \mathrm{K}\left({ }^{\circ} \mathrm{C}\right) \text { experimental } \\
\text { data from DSC }\end{array}$ & \multicolumn{3}{|c|}{$\begin{array}{l}\text { WLF using the universal values } \\
\text { for } C_{1} \text { and } C_{2}\end{array}$} & \multicolumn{4}{|c|}{$\begin{array}{l}\text { WLF using } T g \text { from DSC experimental } \\
\text { data }\end{array}$} \\
\hline & & & & $\operatorname{Tg}(\mathrm{K})$ (predicted) & $\log \left(\eta_{T g}\right)\left(\mathrm{Pa}^{*} \mathrm{~s}\right)$ & $r^{2}$ & $\log \left(\eta_{T g}\right)\left(\mathrm{Pa}^{*} \mathrm{~s}\right)$ & $C_{1}$ & $C_{2}(\mathrm{~K})$ & $r^{2}$ \\
\hline & 16.69 & 81.80 & $229,85(-43.15)$ & $240.44(-32.56)$ & 10.34 & 0.91 & 16.33 & 12.47 & 26.26 & 0.99 \\
\hline J3 & 18.85 & 79.55 & $225,61(-47.39)$ & $228.64(-44.36)$ & 10.66 & 0.95 & 16.18 & 12.72 & 22.41 & 0.88 \\
\hline & 19.04 & 79.35 & $226,45(-46.55)$ & $216.97(-56.03)$ & 11.31 & 0.90 & 15.56 & 13.03 & 18.03 & 0.85 \\
\hline & 17.79 & 80.65 & $230,2(-42.80)$ & $208.01(-64.95)$ & 11.96 & 0.81 & 16.36 & 13.69 & 17.17 & 0.77 \\
\hline & 17.51 & 80.95 & $228,27(-44.73)$ & $223.68(-49.32)$ & 11.89 & 0.98 & 22.11 & 15.64 & 29.61 & 0.99 \\
\hline & 17.84 & 80.60 & $229,66(-43.34)$ & $229.82(-43.17)$ & 10.58 & 0.99 & 23.19 & 14.97 & 35.10 & 0.98 \\
\hline value & $17.95^{a}$ & $80.48^{a}$ & $228.34(-44.66)^{a}$ & $224.59(-48.46)^{a}$ & 11.12 & & 18.29 & 13.75 & 24.76 & \\
\hline 14 & 18.48 & 80.00 & $226,6(-46.40)$ & $227.65(-45.35)$ & 10.45 & 0.99 & 21.37 & 14.46 & 32.13 & 0.99 \\
\hline & 19.39 & 79.05 & $225,51(-47.49)$ & $222.46(-50.54)$ & 10.96 & 0.97 & 19.83 & 14.47 & 26.49 & 0.99 \\
\hline & 18.14 & 80.35 & $224,45(-48.55)$ & $211.50(-61.50)$ & 11.52 & 0.91 & 19.62 & 14.83 & 23.38 & 0.98 \\
\hline & 18.48 & 80.00 & $227,2(-45.80)$ & $229.44(-43.56)$ & 10.34 & 0.98 & 19.61 & 13.89 & 28.85 & 0.96 \\
\hline & 18.67 & 79.80 & $225,29(-47.71)$ & $204.34(-68.66)$ & 11.77 & 0.92 & 20.70 & 15.36 & 25.04 & 0.99 \\
\hline & 18.14 & 80.35 & $230,37(-42.63)$ & $227.09(-45.91)$ & 11.35 & 0.97 & 20.19 & 14.77 & 26.17 & 0.99 \\
\hline Mean value & $18.55^{a}$ & $79.93^{a}$ & $226.57(-46.43)^{a}$ & $220.41(-52.59)^{a}$ & 11.07 & & 20,22 & 14.63 & 27.01 & \\
\hline
\end{tabular}


Table 2

Sugar content of honeys from North (N) and Central region (C) of Argentina. Values with the same letter in the same column are not significantly different $(\mathrm{p}>0.05)$.

\begin{tabular}{|c|c|c|c|c|c|}
\hline Sample $\mathrm{N}^{\circ}$ & $\begin{array}{l}\text { Fructose } \\
(\mathrm{g} / 100 \mathrm{~g})\end{array}$ & $\begin{array}{l}\text { Glucose } \\
(\mathrm{g} / 100 \mathrm{~g})\end{array}$ & Fructose/Glucose & $\begin{array}{l}\text { Sucrose } \\
(\mathrm{g} / 100 \mathrm{~g})\end{array}$ & Maltose $(\mathrm{g} / 100 \mathrm{~g})$ \\
\hline N1 & 41.5 & 23.5 & 1.77 & 1.6 & 5.3 \\
\hline N2 & 39.3 & 26.5 & 1.48 & 2.1 & 2.3 \\
\hline N3 & 39.5 & 26.0 & 1.52 & 1.7 & 4.8 \\
\hline N4 & 40.9 & 26.7 & 1.53 & 1.3 & 3.3 \\
\hline N5 & 39.3 & 28.1 & 1.40 & 0.9 & 3.5 \\
\hline N6 & 38.8 & 26.5 & 1.46 & 1.1 & 3.6 \\
\hline N7 & 41.2 & 25.1 & 1.64 & 1.3 & 6.2 \\
\hline N8 & 40.2 & 24.5 & 1.64 & 0.6 & 4.1 \\
\hline N9 & 42.1 & 24.1 & 1.75 & 1.5 & 6.2 \\
\hline N10 & 39.5 & 25.8 & 1.53 & 1.9 & 5.8 \\
\hline N11 & 39.8 & 27.8 & 1.43 & 1.2 & 3.0 \\
\hline N12 & 38.0 & 28.1 & 1.35 & 1.8 & 4.8 \\
\hline N13 & 39.6 & 27.2 & 1.46 & 1.6 & 3.8 \\
\hline Mean value & $39.9^{a}$ & $26.1^{a}$ & $1.54^{a}$ & $1.4^{a}$ & $4.36^{a}$ \\
\hline $\mathrm{C} 14$ & 43.2 & 31.9 & 1.35 & 1.5 & 4.4 \\
\hline $\mathrm{C} 15$ & 43.6 & 33.6 & 1.30 & 1.4 & 5.2 \\
\hline $\mathrm{C} 16$ & 43.3 & 33.0 & 1.31 & 1.6 & 3.0 \\
\hline $\mathrm{C} 17$ & 43.6 & 32.6 & 1.34 & 1.7 & 5.7 \\
\hline $\mathrm{C} 18$ & 43.0 & 32.0 & 1.34 & 1.7 & 4.9 \\
\hline $\mathrm{C} 19$ & 44.2 & 34.8 & 1.27 & 1.4 & 5.0 \\
\hline $\mathrm{C} 20$ & 43.2 & 33.0 & 1.31 & 0.9 & 3.7 \\
\hline $\mathrm{C} 21$ & 42.8 & 32.6 & 1.31 & 0.8 & 5.9 \\
\hline $\mathrm{C} 22$ & 43.9 & 34.6 & 1.27 & 1.2 & 2.3 \\
\hline $\mathrm{C} 23$ & 43.5 & 33.4 & 1.30 & 1.2 & 5.4 \\
\hline $\mathrm{C} 24$ & 43.0 & 33.1 & 1.29 & 1.1 & 3.1 \\
\hline $\mathrm{C} 25$ & 43.1 & 33.9 & 1.27 & 2.2 & 4.2 \\
\hline $\mathrm{C} 26$ & 43.4 & 33.2 & 1.31 & 1.4 & 6.3 \\
\hline Mean value & $43.5^{b}$ & $33.1^{b}$ & $1.31^{b}$ & $1.4^{a}$ & $4.35^{a}$ \\
\hline
\end{tabular}


Table 3

Parameters calculated through the linearization of Arrhenius, VTF and Power Law models, for honeys from both regions (North and Central region). Values with the same letter in the same column are not significantly different $(\mathrm{p}>0.05)$.

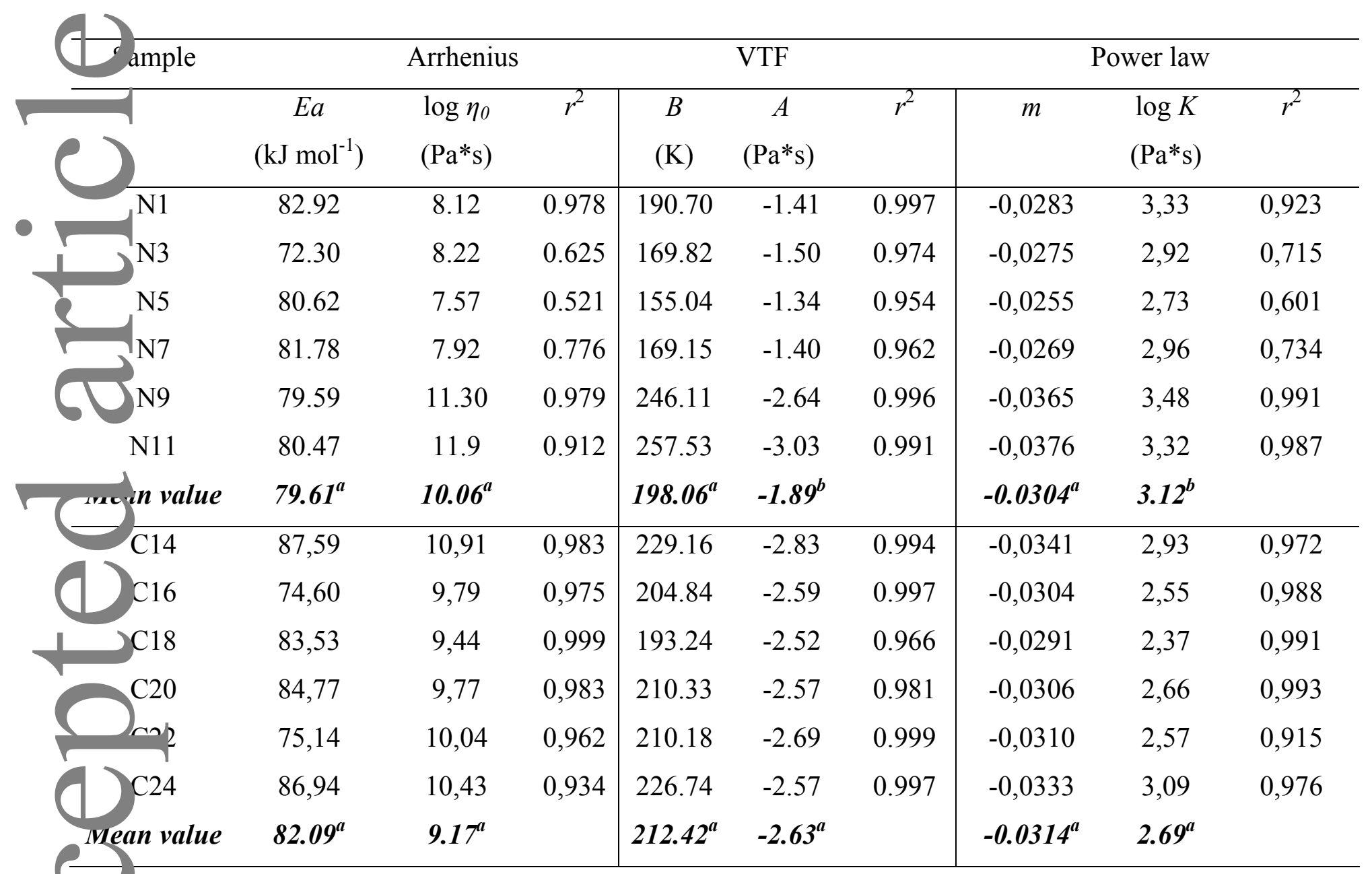


Table 4

Pearson correlation of textural and some physicochemical parameters of honeys from the North region (lower half of the main diagonal of the matrix) and Central region (upper half of the main diagonal of the matrix).

\begin{tabular}{|c|c|c|c|c|c|c|c|c|c|c|c|}
\hline Moisture & 1 & -0.23 & -0.24 & -0.59 & 0.28 & 0.22 & -1.00 & -0.44 & 0.20 & 0.25 & 0.03 \\
\hline Glucose & 0.45 & -0.76 & 1 & 0.01 & -0.26 & -0.92 & 0.25 & 0.47 & -0.37 & -0.47 & -0.44 \\
\hline Maltose & -0.37 & 0.46 & -0.60 & 0.14 & 1 & 0.35 & -0.28 & 0.14 & 0.67 & 0.63 & 0.59 \\
\hline $\mathrm{F} / \mathrm{G}$ & -0.50 & 0.89 & -0.97 & -0.08 & 0.59 & 1 & -0.22 & -0.52 & 0.49 & 0.55 & 0.56 \\
\hline Brix & -1.00 & 0.46 & -0.45 & 0.23 & 0.37 & 0.50 & 1 & 0.44 & -0.20 & -0.25 & -0.03 \\
\hline Hardness & -0.43 & -0.01 & 0.07 & 0.08 & 0.30 & -0.02 & 0.43 & 0.37 & 1 & 0.95 & -0.92 \\
\hline Consistency & -0.25 & -0.05 & 0.09 & 0.29 & 0.24 & -0.06 & 0.25 & 0.21 & 0.96 & 1 & 0.96 \\
\hline Adhesivity & -0.57 & 0.02 & 0.07 & 0.28 & 0.34 & 0.01 & 0.57 & 0.50 & -0.93 & 0.86 & 1 \\
\hline
\end{tabular}

